\title{
DESENVOLVIMENTO MORAL: A POLIDEZ SEGUNDO AS CRIANÇAS
}

\author{
YES DE LA TAILLE \\ Instituto de Psicologia Universidade de São Paulo \\ ytaille@originet.com.br
}

\section{RESUMO}

Após termos apresentado reflexões sobre as relações entre as virtudes e a moral e entre polidez e o desenvolvimento moral, apresentamos quatro pesquisas empíricas com crianças de 6, 9 e 12 anos para responder às seguintes perguntas: 1) A polidez faz parte do universo moral da criança? 2) A polidez já é vista pela criança pequena na sua especificidade em relação às regras propriamente morais? Os dados mostram que: I) a polidez pertence ao universo moral das crianças de 6 a 12 anos, mas com a peculiaridade de sua falta não merecer castigo; 2) que a falta de polidez é, para as crianças de 6 anos, um indício para se julgar o caráter moral de uma pessoa e deixa de sê-lo para as crianças de 12 anos, com uma fase de transição aos 9 anos e 3) que a falta de polidez é vista como conduta de uma certa gravidade nas três faixas etárias. Terminamos o texto com considerações teóricas que procuram mostrar a relevância de uma educação moral que não despreze a polidez. DESENVOLVIMENTO MORAL - CRIANÇAS - EDUCAÇÃO - MORAL

\begin{abstract}
MORAL DEVELOPMENT: CHILDREN'S CONCEPTIONS OF POLITENESS. This text starts with reflections about the relationship between virtues and morality, and between politeness and the moral development. Then, we present and discuss four studies involving 6, 9 and 12-years old children in an attempt to find an empirical answer to the following questions: 1) Does politeness belong to the child's moral universe? 2) Is politeness already seen by young children in its specificity as regards moral rules? Our data show that I) Politeness does belong to the moral universe of 6 to 12-years old children, but with a peculiarity: its lack is not liable to punishment; 2) The absence or presence of politeness is, for the 6-years old child, a sign of the moral character of the person and 3) The lack of politeness is seen as quite a serious fault by the majority of our subjects. We close our paper with some theoretical considerations about the place of politeness in young children's moral education.
\end{abstract}

Este trabalho foi realizado com a colaboração de Claudia Bárbara Domingues e Flávia da Penha Fiorini e obteve financiamento da Fapesp. 
Talvez surpreenda o fato de apresentarmos neste trabalho reflexões e dados empíricos a respeito das concepções infantis sobre a polidez. Com efeito, que importância real pode ter, tanto para a psicologia quanto para a educação, um tema destes, aparentemente tão datado (as "boas maneiras" de antigamente), tão elitista (apanágio da aristocracia preocupada com a "etiqueta") e tão superficial (pura imagem)? E mais ainda: em razão mesmo dessa suposta superficialidade, que relação pode haver entre a polidez e a moralidade? O objetivo deste artigo é justamente o de responder a essas indagações, e isto tanto por meio de uma análise teórica, como da apresentação de alguns dados de pesquisa que, cremos, depõem a favor da necessidade de uma maior atenção, psicológica e educacional, para o tema da polidez no desenvolvimento moral da criança.

Porém, antes de mais nada, se quisermos ter alguma chance de sucesso na articulação entre polidez e moralidade, é preciso nos debruçarmos sobre o objeto desta última. Com efeito, se definirmos moral como restrita à virtude justiça, como o fez Kohlberg (1981), ficamos impedidos de apresentar pesquisas sobre polidez como integrando o campo da psicologia moral. Em compensação, se, como o fazem alguns autores contemporâneos (como Campbell, Christopher, 1996), resgatarmos a definição aristotélica de moral, qual seja, a busca da felicidade, ficamos autorizados a analisar e pesquisar não somente a virtude justiça, mas também outras como generosidade, magnanimidade, gratidão, coragem, prudência, humildade etc. Tal ampliação do universo moral ainda não implica classificar a polidez como virtude moral, mas, no mínimo, permite-nos considerar essa possibilidade. Um primeiro passo de análise impõe-se portanto a nós: pensar se um estudo sobre virtudes pode fazer sentido ético' e enriquecer o campo da psicologia moral. Se a resposta for positiva, caberá então analisar as características singulares da polidez para verificar se elas a credenciam para fazer parte do universo moral.

\section{A MORAL E AS VIRTUDES}

conceito de virtude pode ser definido de, pelo menos, duas formas. A primeira restringe-se à função de determinado objeto: por exemplo, a virtude da faca é cortar, a do olho é enxergar etc. A segunda refere-se a qualidades que uma

I. Neste texto, empregaremos os conceitos de moral e de ética como sinônimos. Tal opção é legítima em razão da origem etimológica de ambas as palavras (ethos e mores, conceitos grego e latino respectivamente e que significam "costumes"). 
pessoa pode possuir e que the conferem valor, despertando a admiração alheia: por exemplo, cantar bem, ser bonito, ser habilidoso com algum instrumento etc. Dentro dessas qualidades, algumas ocupam lugar especial, pois remetem ao caráter da pessoa. É o caso, por exemplo, da coragem, da humildade, da generosidade, da justiça. A diferença básica entre uma virtude como a habilidade física e outra como a generosidade reside no fato de a primeira dizer respeito à qualidade de uma ação e a segundo referir-se a uma qualidade da personalidade. Dito de outra maneira, na habilidade, admiram-se essencialmente as obras, na generosidade, admira-se não somente a ação, mas sobretudo a pessoa. Daí a referência ao conceito de caráter entendido como "leitura ética da personalidade" (Sennett, 1999). Com efeito, virtudes como gratidão, generosidade e coragem são qualidades do caráter da pessoa, enquanto habilidade, beleza, força física não o são. Daqui para frente, nosso emprego da palavra "virtude" remeterá exclusivamente às qualidades referentes ao caráter.

A pergunta que se impõe agora é a seguinte: o tema das virtudes é um tema moral? De fato, se é claro que virtude é valor (uma vez que é entendido como um bem, e que é admirado ou desejado), ainda não está claro que tal valor seja um valor moral. A pergunta pode ser respondida de duas formas diferentes:

A primeira, e a mais simples, remete-nos aos "conteúdos" das diferentes virtudes. Tomemos o exemplo da coragem: é certamente preciso coragem para cometer certos atos terroristas, mas o fato de tais atos causarem a morte indiscriminada de inocentes certamente implica que tal coragem carece de valor moral. Alguém poderá argumentar aqui, e com razão, que o terrorista atribui valor moral a seu ato (em nome da Guerra Santa, por exemplo). Mas o fato é que outras pessoas negarão esse valor. Logo, a coragem não tem valor moral em si. Mesma coisa pode ser dita das outras virtudes (Generosidade com quem? Fidelidade em relação a quê? etc.). Apenas a justiça é, como afirmava Aristóteles, sempre boa, mas mesmo para ela é preciso uma defnição moral: trata-se da justiça divina? Daquela baseada na eqüidade? Em uma palavra, para as virtudes pertencerem ao campo moral, é antes preciso definir esse campo.

Isso nos leva à nossa segunda resposta, que introduzimos com uma citação do filósofo Tugendhat: "o conceito de virtude foi muito tempo deixado de lado pelas éticas modernas” (1993, p.243). Nesse caso, não se trata de avaliar se certos atos de coragem ou provas de gratidão têm valor moral na dependência de seus objetivos ou pessoas-alvo, mas sim de saber se essas virtudes, ou outras, têm relevância para a definição do que seja moral. Ora, para a ética de Aristóteles, elas naturalmente têm, uma vez que a ética é entendida como busca da felicidade e 
que esta é impossível sem o exercício das virtudes (Aristote, 1965). Para a ética cristã, algumas também têm seu lugar, como o atestam as listas elaboradas pelos teólogos da Idade Média (as três virtudes teologais - fé, esperança e caridade - e as quatro virtudes cardinais - justiça, prudência, temperança e coragem). Em compensação, apenas uma delas acaba por reter a atenção dos autores modernos: a justiça baseada na igualdade e na eqüidade (ver, entre outros, Kant, I994; Rawls, 1971; Habermas, 1986), o que faz Maclntyre ( 1981 ) intitular sua importante obra crítica sobre as éticas atuais de After virtue. Pode-se dizer em poucas palavras que a ética atual contempla essencialmente os direitos das pessoas e os deveres decorrentes desses direitos. Com efeito, ser justo com alguém é respeitar seus direitos, enquanto ser generoso ou grato (outras virtudes) é dar ao outro o que lhe falta ou o que ele merece, mas não o que é seu de direito. Assim, as virtudes passam a ocupar lugar periférico, lugar este claramente atestado pelas pesquisas em psicologia moral. Para ficarmos com três dos principais autores da área, verificamos que Piaget ( 1992) pede a seus sujeitos que emitam julgamentos sobre roubo (direito à propriedade privada), mentira (direito de se saber a verdade), punições (merecimento), que Kohlberg ( $198 \mathrm{I}$ ) pede aos seus que comparem e estabeleçam uma hierarquia para o direito à propriedade privada e para o direito à vida (o famoso dilema de Heinz) e que Turiel ( 1983) verifica com crianças de várias culturas se elas colocam em categorias diferentes ações que ferem o bem-estar alheio, portanto que ferem um direito, e outras que fogem às convenções sociais (como regras de vestimenta) ou que representam opções puramente individuais (como ir ou não a uma festa). Portanto, para esses autores, que fizeram e fazem escola, o comportamento moral é aquele que corresponde a deveres, e tais deveres derivam de direitos alheios. E, nessa perspectiva, dentre as virtudes, somente uma pode ser chamada de moral, a justiça. Outras, como generosidade, gratidão, fidelidade e humildade não foram objeto de pesquisa, o que faz Flanagan afirmar que "ignoramos, do ponto de vista psicológico, o que é uma virtude" (1996, p. I 5). A afirmação é verdadeira, salvo, como acabamos de dizer, em relação à justiça: sobre ela temos grande quantidade de pesquisas, que se acumulam desde o estudo pioneiro de Piaget sobre o Juízo moral na criança ( 1992).

Há, todavia, notável exceção no campo da psicologia moral: Carol Gilligan (1982, 1988). Como se sabe, a autora propôs que, ao lado de uma ética da justiça, que, segundo ela, domina os juízos masculinos, considere-se a existência de uma ética do cuidado (care), supostamente mais presente nas apreciações morais das mulheres. A "voz diferente", a feminina, ouvida por Gilligan, suscitou duas polêmicas. A primeira, que não nos interessa aqui, diz respeito à relação entre 
desenvolvimento moral e gênero. A segunda polêmica, diretamente relacionada ao tema das virtudes, refere-se à própria definição da moral: de fato, enquanto uma ética da justiça considera o sujeito moral como submetido a deveres decorrentes de direitos alheios, uma ética do cuidado, que se caracteriza por levar em conta a singularidade e as necessidades específicas de cada pessoa, não pode ser derivada dos direitos da pessoa contemplada. A virtude típica da ética do cuidado é a generosidade. Ora, o que é ser generoso? É, segundo a expressão de ComteSponville (1995), fazer um dom de sipara contemplar uma falta em outrem. Notese que o ato generoso pode, para certas pessoas, corresponder a um dever (no sentido do imperativo categórico de Kant), mas tal dever não é derivado do reconhecimento de um direito alheio. Em uma palavra, a virtude generosidade não se confunde com a virtude justiça. Logo, não é errado dizer que Gilligan propôs uma ampliação do domínio moral para pelo menos duas virtudes. Será por isto criticada por autores como Kohlberg ( 198 I) e Habermas (1986), que preferem restringir a moral ao campo da justiça, mas também por outros como Campbell e Cristopher ( 1996) e Flanagan ( 1996) que, embora reconhecendo o valor de sua "dissidência", pensam que ela foi demasiadamente tímida: por que apenas duas virtudes e não mais? O debate está instalado no campo da psicologia moral e também da filosofia, como o demonstram as obras já citadas de Maclntyre, Flanagan, Tugendhat e ComteSponville, entre outros.

Em resumo, nossa segunda resposta a respeito do possível caráter moral das virtudes é a seguinte: dependendo da perspectiva ética adotada, elas pertencem, ou não, ao campo da moral. Interessantemente, o tema das virtudes tem voltado ultimamente à tona, tanto na filosofia quanto na psicologia, fato que, por si só, poderia justificar pesquisas psicológicas sobre elas.

Mas vamos, agora, nos colocar do ponto de vista estritamente psicológico e procurar mostrar que pesquisas sobre virtudes justificam-se mesmo que permaneçamos com uma definição de ética que não as contemple.

\section{A PSICOLOGIA MORAL E AS VIRTUDES}

Três razões serão apresentadas em defesa de estudos psicológicos das virtudes.

A primeira refere-se às disposições de caráter necessárias à ação moral. Como escreve Comte-Sponville: "Na maioria dos casos, sabemos muito bem o que deveríamos fazer ou o que faríamos se fôssemos santos ou heróis. Mas não ousamos. Não o queremos. Não é o julgamento que faz falta: é a coragem, a generosidade" (1995, p.212). Aristóteles já falava que a coragem é condição ne- 
cessária para o exercício de várias virtudes: com efeito, para permanecermos éticos, às vezes precisamos enfrentar obstáculos de várias ordens, notadamente, riscos. O que seria da virtude justiça se pessoas como Rosa Parks, Ghandi e Martin Luther King não tivessem tido a coragem de desafiar o poder?

A segunda razão que, a nosso ver, pode levar o psicólogo a debruçar-se sobre outras virtudes é que a justiça é o lugar que elas parecem ocupar na gênese da moralidade. Reflitamos, por exemplo, sobre a seguinte explicação dada por Piaget: "É quando a criança habitua-se a agir do ponto de vista dos próximos, e preocupa-se mais em agradá-los do que a eles obedecer, que ela chega a julgar em razão das intenções" (1992, p. I05, tradução nossa). Esta frase traz um ponto clássico da perspectiva piagetiana: a passagem de uma "moral da obediência" (nome que também designa a heteronomia) para outra, superior, que leva em conta as intenções dos agentes, a moral autônoma, na qual o realismo moral é superado. Mas a citação traz mais do que isso. Ela refere-se a uma explicação causal para dar conta da evolução moral e, é o que nos interessa nesse caso, nela está afirmado que o que explica a passagem da heteronomia para a autonomia não é tanto uma tomada de consciência do outro como sujeito de direitos, mas antes a tendência a considerá-lo na sua singularidade: é o que sugere o emprego do verbo "agradar" (faire plaisir). Em uma palavra, Piaget nos fala mais, nessa citação, em generosidade do que em justiça, embora, na sua própria teoria, a autonomia represente a vitória do princípio de justiça sobre a mera obediência à autoridade. Vale dizer que podemos construir a hipótese de que, no caminho para a construção do ideal de justiça, a generosidade (e outras virtudes altruístas, que levam em conta o outro na sua especificidade) desempenha um papel. Na autonomia (sobretudo como definida por Kohlberg), a justiça precederá, do ponto de vista lógico (implicações), a generosidade, mas esta talvez preceda a justiça do ponto de vista cronológico. Vamos pensar outro exemplo. Tugendhat, em obra já citada (1993), diz discordar de Piaget quando este baseia a moral heterônoma sobre o respeito pela autoridade. Para ele, um dos pontos essenciais a ser pensado na relação filhos/pais não é o fato de os segundos terem autoridade sobre os primeiros, mas sim a confiança que eles despertam. O moral sense, condição necessária ao pensar e agir morais do filósofo, teria suas raízes na confiança que as crianças desenvolvem em relação a seus progenitores e outras pessoas significativas. Nomeando o processo mediante as virtudes, teríamos o lugar importante da fidelidade: é porque os pais mostramse fiéis a seus filhos e às palavras que empenham em relação a eles que as crianças penetrariam no mundo da moral, não permanecendo no puro medo das sanções. É evidente que a fidelidade sofrerá radicais mudanças de interpretação no decor- 
rer do desenvolvimento moral, mas o fato é que, segundo a perspectiva de Tugendhat, essa virtude encontrar-se-ia precocemente na gênese da moralidade humana.

Os dois exemplos que demos nos serviram para defender a seguinte tese: embora algumas virtudes possam ser descartadas do sistema axiomático (definição do objeto, que pode, como em Kohlberg, privilegiar uma, a justiça), elas podem desempenhar um papel na construção da moralidade. Referindo-se a um sistema axiomático, o Direito, Piaget escreveu que "é, sem dúvida, o dever do axiomático cortar o cordão umbilical para dissociar a construção formal de suas amarras com o real, mas cabe ao sociólogo lembrar que este cordão existiu e que seu papel foi fundamental à alimentação do direito embrionário" (1977, p.66). No plano psicológico agora, talvez as virtudes sejam fundamentais para a alimentação da gênese da moral. Essa possibilidade é, como veremos adiante, a principal razão pela qual propomos uma pesquisa sobre as noções de polidez na criança.

Falta vermos a terceira razão pela qual se sustenta, do ponto de vista psicológico, a realização de reflexões e pesquisas sobre virtudes. Uma nova perspectiva teórica em psicologia moral tem sido adotada por vários autores nos últimos anos: analisar o pensar e agir morais na sua articulação com o Eu, ou identidade (Colby, Damon, 1993; Blasi, 1993; Flanagan, 1996; Taylor, 1998; Gilligan, 1988; La Taille, 2000; Campbell, Cristopher, 1996). A expressão inglesa moral self tem nomeado tal perspectiva que é sintetizada na citação: "Parece seguro concluir que algumas pessoas unem a moralidade e o Eu numa proporção maior do que outras" (Colby, Damon, 1993, p. I 5 I). A afirmação é inspirada em pesquisa com pessoas de vida moral exemplar: para elas, ser moral e ser elas mesmas é eqüivalente; vale dizer que os valores morais estão, nelas, intimamente associados à sua identidade. Blasi apresenta uma síntese semelhante: "Em termos puramente conceituais, parece possível que o mais alto nível de integração moral esteja realizado quando a compreensão e o interesse morais fazem parte do autoconceito" (Blasi, 1995, p.232). Ora, o que é autoconceito senão um conjunto de representações de si que são valorativas? "Sou valor porque sou, sou porque sou valor", escreve Perron ( 1991, p.24, tradução nossa). Assim, os valores associados às representações de si podem ser não morais (por exemplo, ser bonito, rico, inteligente), podem até ser imorais (ser violento, despótico, "esperto" etc.) e podem ser morais. E no campo dos valores morais, é bem provável que virtudes como generosidade, gratidão e coragem possam ser associadas ao Eu. De fato, não se vê porque apenas a justiça teria precedência. Em resumo, a nova perspectiva teórica do moral self(ou "personalidade moral") parece sugerir que sejam estudados vários valores que podem 
compor as representações de si (e não apenas um), fato que nos remete a um estudo das virtudes, uma vez que representam, como já o escrevemos, uma leitura ética da personalidade.

Podemos assim resumir o que foi escrito até agora: I) uma virtude é um valor pelo qual se avalia o caráter de uma pessoa, 2) tal valor pode, dependendo do sistema ético adotado, ser um valor moral, 3) mesmo que restrinjamos a ética à virtude "justiça", as demais podem corresponder a qualidades de caráter necessárias à sua efetivação em ação, 4) as demais virtudes também podem ter uma função na gênese da moralidade (mesmo definida como restrita à justiça) e 5) podem compor os sistemas de valores da "personalidade moral" (moral self).

E assim finalizamos nossos argumentos em favor do interesse que um estudo psicológico das virtudes pode ter para a área da psicologia moral e, em conseqüência, para a educação moral. É verdade que, em relação a esta última, uma "pedagogia das virtudes" pode levar à volta de práticas autoritárias e moralistas, ferindo a autonomia da criança e do aluno. Voltaremos a este tema no final do artigo.

\section{A POLIDEZ}

Se tivermos tido um certo sucesso em sustentar que um estudo psicológico das virtudes pode oferecer perspectivas teóricas (e práticas), isto ainda não é suficiente para justificar a inclusão da polidez entre as virtudes a serem pesquisadas. Devemos então nos debruçar sobre a chamada "boa educação". Para isso, seguiremos o esquema empregado para analisar a relação entre as virtudes e a moral: verificar o caráter universal da polidez, sua relação com a moral e suas dimensões psicológicas, notadamente na gênese da moralidade infantil.

Antes de mais nada, devemos definir a polidez: trata-se de formas de falar e/ou de agir convencionais, nas relações sociais, como, por exemplo, falar "bomdia", "desculpe", "obrigado", sentar-se de determinadas formas etc. $\bigcirc$ aspecto convencional das expressões da polidez é essencial: a rigor, basta um acordo para que determinadas formas de agir passem a ser consideradas como formas de polidez, e outras como contrárias a ela², logo, o que num determinado grupo social "se faz" não necessariamente é aconselhado em outros. Portanto, as formas

2. Por exemplo, os "palavrões" são muito mais aceitos hoje em dia. Décadas atrás, qualquer um deles era considerado como expressão clara de má educação. 
da polidez não são universais (como parecem ser certos mandamentos éticos, como o não matar, por motivos egoístas ${ }^{3}$ ). Todavia, a despeito de diferenças de conteúdos, a presença de regras de polidez é fenômeno universal. De fato, que sociedade, que comunidade, que classe social não tem as suas? Tal universalidade não deixa de ser aparentemente paradoxal: como algo tão superficial da conduta humana pode estar presente e até ser exigido em todas as formas de civilização? Esta pergunta nos leva à relação entre a virtude polidez e a moral.

Mas será a polidez uma virtude? Se a compararmos à justiça, à generosidade, à coragem, e a outras virtudes ainda, ela não parece ter muito peso. A polidez é mais um hábito ${ }^{4}$, algo que se faz maquinalmente, sem esforço e reflexão. Ora, virtudes como generosidade, justiça e coragem pedem, não raras vezes, esforço (contra tendências adversas) e reflexão (resolver dilemas) e, assim, apontam para a excelência. Como a polidez nada parece exigir de quem a pratica, poder-se-ia dizer que não é uma virtude. No entanto, descartá-la parece-nos um erro. Embora longe da excelência, a polidez não deixa de ser uma qualidade que, em geral, é notada e apreciada. Não estamos pensando aqui na oposição entre as "boas maneiras" e a vulgaridade, que remete à oposição entre um maior e menor domínio da etiqueta: de fato, uma pessoa que domina as "boas maneiras" pode, dependendo do uso que faz delas, aproximar-se mais da afetação do que da polidez, e uma pessoa considerada vulgar pelo uso pouco lapidado da fala pode muito bem ser polida no trato com as demais pessoas. Há algo de elegância, de certa fineza, no que se chama de polidez, aquelas são necessárias para que esta seja admirada e notada. Ficamos com a análise de Comte-Sponville (1995) que afirma que ela é a mais pobre, a mais superficial, a mais ambígua e a mais discutível das virtudes, mas que tem seu valor, merecendo, assim, pelo menos o nome de "pequena virtude" (p. I5).

E terá a polidez alguma relação com a moral? Acreditamos que sim. Aqui, também, ela merece o nome de "pequena virtude", pois em alguns aspectos ela nada tem de moral. Já vimos que seu exercício pouco ou nada exige de esforço e reflexão. A isso devemos acrescentar que ela não pressupõe sinceridade (quem

3. Matar pela pátria é freqüentemente aceito.

4. Aristóteles considerava que o exercício das virtudes dependia do hábito porque deviam ser praticadas para serem realmente incorporadas à personalidade, transformando-se numa "segunda natureza". Hábito não era considerado por ele no sentido pejorativo às vezes atribuído a esta palavra. 
fala "desculpe" pode não estar, de fato, importando-se com o que fez, mas simplesmente empregando a palavra convencional) e que ela pode até ser hipócrita (tratar com boa educação alguém que se quer agredir). Logo, a polidez em nada nos informa realmente sobre a índole moral de quem a pratica: há torturadores e ladrões polidos (e isto pode torná-los ainda mais detestáveis!), assim como há pessoas grosseiras que podem ter, como se diz, um "bom coração".

Porém, tudo não está dito sobre ela se nos limitarmos a esta evidente fraqueza valorativa da polidez. Há pelo menos um aspecto que a relaciona à moral: salvo nos casos de clara hipocrisia, a polidez é sinal de mínima expressão do respeito moral pelo outro. $\bigcirc$ fato verifica-se facilmente pela inversa: a ausência de certas formas de boa educação é freqüentemente sentido como agressão, desprezo, portanto, desrespeito. Não cumprimentar alguém, assim como não pedir desculpas ou "por favor", pode significar que a pessoa que está do nosso lado simplesmente não existe para nós, ou que é considerada ser inferior (vêem-se pessoas que somente cumprimentam seus "iguais" e não seus empregados). A polidez traduz certa deferência para com outrem, o reconhecimento de sua existência e valor. É por esta razão que se costuma associar polidez à civilidade, e sua ausência à incivilidade, que é uma forma de violência. Assim, a ausência de polidez freqüentemente se deve não ao fato de a educação ter falhado em ensinar "boas maneiras", mas sim ao fato de a pessoa não polida ser autocentrada, ou egoísta, ou ainda considerar-se como socialmente superior. Concordamos com LucchesiBelzane quando escreve que:

A polidez comanda abolir as diferenças de classe entre os homens, comanda falar com o rico assim como se fala com o pobre, com o cidadão comum como com o poderoso (...) vista sob este ângulo, a polidez está mais próxima do respeito moral. (199|, p.33)

Em resumo, as diversas formas da polidez, mesmo que superficiais e não sinceras, podem traduzir atitudes respeitosas, de consideração pelo outro; logo, a sua ausência pode traduzir intenção de desprezo, de agressão, de violência ${ }^{5}$. É nesse sentido que dizemos que há algo de moral na polidez: se ela em si pouco tem de moral, seu uso pode ter.

5. Laterman (2000) verificou que as diversas formas de incivilidade (definida como transgressão aos códigos elementares da vida em sociedade) representam uma das queixas mais freqüentes do cotidiano escolar feitas pelo alunos. 
Falta analisarmos a dimensão psicológica colocando-nos a seguinte pergunta: a aprendizagem das formas de polidez desempenha algum papel no desenvolvimento moral da criança? Fizemos, como apontado anteriormente, a hipótese de que virtudes como generosidade e fidelidade poderiam desempenhar um papel causal na gênese da moralidade (e isso mesmo que se restrinja a moral à virtude justiça). Ora, será que a polidez pode ser colocada na lista das virtudes que alimentam o desenvolvimento moral? A pesquisa que vamos relatar em seguida tem por objetivo avaliar essa possibilidade. Mas antes de apresentá-la, é necessário colocar argumentos que a tornem verossímil.

Comte-Sponville, um dos únicos filósofos que, a nosso conhecimento, dá algum valor à polidez, faz a seguinte afirmação:

A polidez (aquilo que não se faz) é anterior à moral (aquilo que não se devefazer), a qual somente se constituirá paulatinamente, como uma polidez interiorizada, liberada das aparências e de interesses, e toda concentrada na intenção (da qual a polidez é desprovida). Mas poderia a moral emergir se a polidez não estivesse presente antes? As boas maneiras precedem as boas ações, e levam a elas. (1995, p. 18, grifo do autor)

Comte-Sponville não é psicólogo e nem traz referências à psicologia para sustentar sua afirmação de caráter genético. Remete-se apenas ao "bom senso" e também a escritos de Kant sobre pedagogia. Com efeito, neles, Kant (|98|) coloca que a primeira fase da educação deve ser a da disciplina imposta pelos adultos: tal disciplina seria condição necessária para podar o que, na criança, é primitivo e selvagem, e assim permitir a instrução propriamente dita, notadamente aquela reservada à moral. Embora Kant não tenha falado diretamente de polidez, é possível deduzir que ele não desprezava a imposição das boas maneiras à criança pequena: elas não deixam de ser uma forma de disciplina do falar e do comportarse. $\bigcirc$ que praticamente cem anos de pesquisas psicológicas sobre o desenvolvimento moral nos permitem dizer sobre a posição de Kant e Comte-Sponville?

Com exceção de Turiel (1 983), que vê na criança pequena (6 anos de idade) um sujeito já capaz de distinguir o domínio moral do convencional, os demais autores costumam concordar com a tese segundo a qual a moral propriamente dita somente pode fazer parte do universo infantil a partir dos 8, 9 anos de idade. Antes, criança seria pré-moral, sua obediência a regras (consideradas morais pelos adultos) dever-se-ia ao medo que tem de perder o amor dos pais (Freud, 1991), ao medo da punição (o estágio um, segundo Kohlberg) ou a uma mistura de admiração e medo, sentida em relação aos pais (Piaget, 1992). Portanto, segundo os 
principais autores da psicologia moral, algo antecede, do ponto de vista genético, a moralidade propriamente dita, e esse algo é a imposição de certas formas de conduta coerentes com a moral, mas ainda não interpretadas como tal pela criança pequena. Como a polidez costuma ser uma dessas formas de conduta, é possível aceitar o fato de que ela preceda a moral.

Porém, isso ainda não significa dizer que ela prepare a moral! Antecedência não implica necessariamente causalidade. Para analisar seu possível papel causal, é preciso não somente conhecermos as descrições que Freud, Kohlberg e Piaget (para nos limitarmos aos autores que acabamos de citar) fizeram do desenvolvimento moral, mas também lembrarmos como explicam tal desenvolvimento.

Freud fala claramente em interiorização, termo empregado por ComteSponville: aquilo que é, num primeiro momento, imposto pelos pais torna-se parte do aparelho psíquico (superego) que será responsável pela "imposição interior" da consciência. Aqui, porém, surge um problema em relação à polidez: dificilmente sua ausência causará, no "mal-educado" adulto, o sentimento de culpa próprio das armas do superego para coagir o ego. Aliás, reencontramos aqui uma dificuldade própria ao sistema freudiano: se o superego é formado a partir das imposições dos pais (e das idealizações feitas pela criança a respeito deles), como ele, o superego, pode ser essencialmente o lugar dos valores e regras morais, ou como o sujeito, posteriormente, fará a diferença entre eles e outros valores e regras? A despeito da dificuldade, a idéia de Comte-Sponville, por aceitar a tese da interiorização, está de certa maneira em sintonia com o sistema freudiano. Mas o que dizer de teorias, como as de Piaget e Kohlberg, que não prevêem uma simples interiorização, mas sim uma construção da moral? Que lugar pode ter a polidez nessa construção? Ora, é justamente nessa perspectiva teórica que, cremos, podemos achar-lhe um lugar. Como a abordagem de Kohlberg é, nas grandes linhas, uma sofisticação de algumas idéias básicas de Piaget (e também uma redução, por assimilar a moral exclusivamente à justiça, coisa que Piaget não fez, nem sugeriu ${ }^{6}$ ) limitemos nossa análise a este último autor.

Como se sabe, Piaget estabeleceu a presença de duas morais na criança: a heteronomia e a autonomia. Embora esta última oponha-se à primeira do ponto de vista dos fundamentos (autoridade versus contrato), ela representa uma superação daquela: a autonomia pode substituir a heteronomia, mas, nesse caso, ela

6. Piaget limita-se a dizer que a justiça é a mais racional das virtudes morais. Para maiores análises da redução efetuada por Kohlberg em relação à teoria de Piaget, ver Flanagan ( 1996). 
nasce da heteronomia que é o primeiro estágio do desenvolvimento moral. Ora, duas características da polidez prevêem um lugar possível para ela na moral heterônoma. Em primeiro lugar, a polidez sendo um conjunto de regras precisas cuja observância depende apenas de seu entendimento "ao pé da letra", e tais regras costumam ser impostas e cobradas pelos adultos, as chamadas "boas maneiras" são perfeitamente assimiláveis pelas crianças menores: na verdade, a moral, para elas, é um conjunto de regras que, como bem o expressa Comte-Sponville, remete ao que se faz. Em segundo lugar, e em decorrência, como a criança heterônoma ainda não penetrou o "espírito das regras" e ainda não as faz depender da intencionalidade, é bem provável que as regras de polidez apareçam para ela num primeiro momento, como morais elas mesmas. Piaget havia verificado que as crianças menores associam todas as formas proibidas de expressão verbal (como o palavrão) com a mentira. Ora, é aceitável pensar que acontece o mesmo com a polidez: essas regras mínimas de convívio talvez revistam, no início do desenvolvimento, um caráter moral. Em uma palavra, fazemos a hipótese de que a polidez faz parte do universo moral da criança menor, hipótese cuja pertinência vamos averiguar em nossa pesquisa empírica.

Será que dizer que a polidez faz parte do universo moral da criança menor (se educada para tanto, é claro) implica afirmar que desempenha algum papel no desenvolvimento? Em parte sim, pelo menos da perspectiva construtivista, pois esta prevê que as estruturas superiores alimentam-se das formas e dos conteúdos das inferiores. Assim, se a polidez for, de fato, parte integrante do universo moral das crianças heterônomas, a construção da autonomia dependerá inevitavelmente de abstrações reflexivas e empíricas realizadas sobre as regras de boa educação (e sobre as demais) e seus efeitos no meio social. E há mais: uma vez que a polidez, como vimos acima, não deixa de representar uma tradução do respeito por outrem e de igualdade entre as pessoas, é possível que sua prática já coloque a criança no caminho dos dois eixos básicos da moralidade (respeito e igualdade). $\mathrm{Na}$ autonomia, o sujeito guardará da polidez apenas o aspecto deferência em relação a outrem, compreendendo que a real consideração moral pede muito mais do que o emprego de algumas fórmulas verbais e posturas corporais. Mas de onde viria tal sofisticação do juízo moral se ele não pudesse alimentar-se de regras precisas e concretas? Não estamos querendo dizer que a aprendizagem da polidez é condição necessária ao desenvolvimento moral (há tantas outras regras que podem desencadear abstrações reflexivas e empíricas), apenas queremos assinalar que pode cumprir uma função. Voltaremos a essa questão de educação moral no final do texto. 
$\mathrm{Na}$ esperança de termos equacionado satisfatoriamente as principais razões que nos levaram a nos debruçar sobre as relações entre a polidez e o desenvolvimento moral, vamos agora explicitar as duas perguntas centrais que inspiraram as pesquisas empíricas que passaremos a apresentar: I) A polidez faz parte do universo moral da criança? E até que idade? e 2) A polidez já é vista pela criança pequena na sua especificidade em relação às regras propriamente morais?

\section{MÉTODO}

Entrevistamos individualmente 90 sujeitos, alunos de uma instituição de ensino particular, divididos em três grupos: 30 sujeitos de 6 anos, 30 de 9 anos e 30 de 12 anos. Cada grupo é formado de 15 meninos e 15 meninas ${ }^{7}$ ). $O$ método empregado foi o da entrevista clínica baseada em algumas perguntas abertas (Estudo I) e em algumas situações-problema (Estudos 2 a 4). Os protocolos foram lidos e analisados por dois juízes independentes.

\section{Estudo I}

Este estudo consistiu em uma entrevista aberta baseada nas seguintes perguntas:

1) O que é a boa educação ${ }^{8}$ ? Dê alguns exemplos.

2) Dê exemplos de má educação?

3) $\bigcirc$ que se deve fazer com pessoas mal-educadas? Por quê?

\section{Estudo 2}

O estudo 2 apresenta uma pequena situação-problema para averiguar se os sujeitos pensam que a falta de polidez numa pessoa é indício de que ela transgredirá regras morais (no caso, dois danos materiais). Seguem a história e as questões colocadas aos sujeitos (depois de nos certificarmos que eles compreenderam a história).

7. Como nossos dados não apresentaram diferenças entre as respostas de meninos e meninas, desprezaremos a diferença de gênero na apresentação e análise dos resultados.

8. Como a palavra polidez é de raro emprego, até em adultos, optamos pela expressão mais freqüente "boa educação". 
Rodolfo (Márciaª ) e Luís (Patrícia) são irmãos, mas são muito diferentes. Rodolfo sempre cumprimenta as pessoas, diz obrigado e pede por favor. Luís não faz nada disto: não costuma dizer obrigado, não pede por favor e nunca cumprimenta as pessoas. Um dia, a mãe deles percebe que seu canteiro de flores foi pisoteado por um de seus filhos.

- Quem você acha que pisoteou o canteiro? Por quê?

- Você tem certeza? É sempre assim?

Num outro dia, a mãe encontrou um vaso quebrado.

- Ela podia saber quem foi que quebrou? Por quê?

- Ela teria certeza? Por quê?

\section{Estudo 3}

O estudo 3 complementa o anterior: trata-se de saber se os sujeitos pensam que a falta de educação é indício de índole moral suspeita. Mas, agora, em vez de dar como exemplo a transgressão a uma regra precisa, abordamos o tema da virtude: a falta de polidez seria indício de falta de coragem ou generosidade (ou senso de justiça)? Eis a história e as perguntas da entrevista clínica:

Havia um menino bem-educado e outro mal-educado. Um dia, um deles viu outro menino sendo atacado por um grupo; eles queriam bater no garoto. Então, o menino que viu foi lá e ajudou o menino que ia apanhar.

- Dá para saber qual ajudou: o bem-educado ou o mal-educado?

- Dá para ter certeza? Por quê?

\section{Estudo 4}

O último estudo visou verificar como nossos sujeitos hierarquizam, em termos de gravidade, uma falta de polidez e um dano material causado por desleixo.

Na casa de Vítor (Gabriela), não tinha mais açúcar. Então ele foi até a casa da vizinha pedir uma xícara de açúcar. A vizinha concordou, pegou uma de suas xícaras, encheu-a de açúcar e a deu ao menino. Vítor pegou a xícara, virou as costas e foi embora, sem dizer obrigado.

9. Colocamos entre parênteses o nome feminino que empregamos para entrevistar sujeitos do sexo feminino. 
Na casa de outro menino, Pedro (Taís), também não tinha açúcar e então ele foi até a casa da vizinha pedir. A vizinha deu o açúcar numa xícara e Pedro disse obrigado. Voltando para casa, Pedro não toma cuidado e brinca de equilibrar a xícara na palma da mão. Ele a deixa cair e, ao cair, a xícara se quebra.

- Os dois agiram errado? Por quê?

- Qual agiu mais errado? Por quê?

\section{RESULTADOS E ANÁLISE}

\section{Estudo I}

Os dois primeiros temas do estudo I (exemplos de boa e de má educação) dizem diretamente respeito a uma de nossas duas perguntas gerais, a saber: a polidez faz parte do universo moral da criança? E até que idade? Ora, recebemos exemplos que cobrem amplo leque de deveres. Os exemplos de boa educação vão de "não bater", "não roubar", "não mentir" a "não falar palavrão", "falar obrigado", "pedir desculpas", passando por aspectos mais gerais como "obedecer", "gostar do irmão", "respeitar". Mesma coisa acontece para os exemplos de má educação: o mal-educado pode ser o que bate, o que mente, o que desobedece e também o que falta às boas maneiras. Se classificarmos as respostas em duas categorias: uma reservada apenas aos bons modos (definição clássica da polidez, como "falar obrigado", "comer de boca fechada" ou "pedir desculpas") e outra que inclui os deveres, com decorrências claramente morais (como "não bater", "respeitar" etc.), verificaremos que, em todas as idades, a polidez é assimilada a um dever moral pela maioria dos sujeitos (tabelas I e 2).

\section{TABELA I}

PORCENTAGEM DE EXEMPLOS DE BOA EDUCAÇÃO

\begin{tabular}{|l|c|c|c|}
\hline & $6 \operatorname{anos}(\mathrm{N}=77)^{*}$ & $9 \operatorname{anos}(\mathrm{N}=69)$ & 12 anos (N=81) \\
\hline Bons modos & $9,9 \%$ & $24,6 \%$ & $28,6 \%$ \\
\hline Moral & $88,9 \%$ & $75,4 \%$ & $71,4 \%$ \\
\hline Não sabe & $1,2 \%$ & $0 \%$ & $0 \%$ \\
\hline
\end{tabular}

* Como nossos sujeitos deram várias respostas, o N representa o número total de respostas obtidas. 


\section{TABELA 2}

\section{PORCENTAGEM DE EXEMPLOS DE MÁ EDUCAÇÃO}

\begin{tabular}{|l|c|c|c|}
\hline & 6 anos $(\mathrm{N}=84)^{*}$ & 9 anos $(\mathrm{N}=61)$ & 12 anos $(\mathrm{N}=75)$ \\
\hline Bons modos & $16,7 \%$ & $18 \%$ & $26,7 \%$ \\
\hline Moral & $80,9 \%$ & $82 \%$ & $73,3 \%$ \\
\hline Não sabe & $2,4 \%$ & $0 \%$ & $0 \%$ \\
\hline
\end{tabular}

* Como nossos sujeitos deram várias respostas, o N representa o número total de respostas obtidas.

Portanto, os dados são claros para um começo de resposta à nossa indagação geral: a maioria de nossos sujeitos assimila a boa educação ao respeito pelas regras morais, e a má, à transgressão dessas. Para a maioria deles, ser bem-educado é mais do que simplesmente comportar-se segundo os mandamentos das boas maneiras. Podemos então chegar à conclusão de que, para nossos sujeitos, a polidez faz parte do universo moral? Ainda não. Com efeito, chama a atenção o fato de não termos encontrado uma gênese. Seria de se esperar que a assimilação da polidez à moral fosse mais significativa nas crianças menores e que diminuísse nos sujeitos mais velhos. Ora, isso não aconteceu, o que pode nos levar a questionar o método: talvez tenhamos simplesmente verificado não o juízo de uma eqüivalência valorativa entre a polidez e regras como "não roubar" ou "não bater", mas sim uma falta de precisão conceitual, a "boa educação" sendo uma expressão verbal geral na qual cabem todas as formas desejáveis ou obrigatórias de conduta.

A segunda pergunta que fizemos a nossos sujeitos no estudo I teve como objetivo avaliar o lugar da polidez no universo moral pelo tema do castigo. Segundo Durkheim (1974), para sabermos que regras uma sociedade considera moral, devemos verificar que sua transgressão leva a alguma forma de castigo. Fizemos exatamente essa pergunta aos sujeitos: o que, segundo eles, deve ser feito com a pessoa mal-educada? As respostas que obtivemos foram, como costuma acontecer em entrevistas abertas, bastante variadas. Alguns sujeitos falaram em castigo, outros em dar uma chance, outros ainda em ser mal-educado de volta. Houve também aqueles que frisaram a necessidade de ensinar a boa educação. Na tabela 3, mostramos os dados repartidos em duas classes: numa, que chamamos de educação, colocamos as respostas que falam em ensinar a pessoa mal-educada a ser polida e, noutra, chamada de castigo, colocamos as respostas que colocam alguma forma de sanção (seja por reciprocidade, como ignorar o mal-educado ou ser mal-educado com ele também, seja expiatória, como colocar de castigo ou chamar alguma autoridade para que tome uma providência). 


\section{TABELA 3}

PORCENTAGEM DE RESPOSTAS REFERENTES AO QUE SE DEVE FAZER COM UMA PESSOA MAL-EDUCADA

\begin{tabular}{|l|c|c|c|}
\hline & $6 \operatorname{anos}(\mathrm{N}=32 *)$ & $9 \operatorname{anos}(\mathrm{N}=37)$ & $12 \operatorname{anos}(\mathrm{N}=32)$ \\
\hline Educação & $48 \%$ & $77 \%$ & $67 \%$ \\
\hline Castigo & $52 \%$ & $23 \%$ & $33 \%$ \\
\hline
\end{tabular}

* Como nossos sujeitos deram várias respostas, o N representa o número total de respostas obtidas.

Segundo a hipótese de que as respostas que apontam para atos educativos traduzem uma diferenciação feita entre a falta de polidez e transgressões claramente morais (merecedoras de castigo), temos que, aos 6 anos de idade, praticamente metade de nossa amostra (48\%) já percebe a singularidade da polidez, o seu aspecto convencional. E encontramos um indício de gênese: aos 9 e 12 anos as porcentagens dos sujeitos que escolhem o ensinar a polidez $(77 \%$ e $67 \%$ respectivamente) são um pouco superiores àquela verificada aos 6 anos, mas este fato não nos deve fazer esquecer que, já nesta faixa etária, quase metade dos sujeitos pensam como seus colegas mais velhos. Ficamos portanto num impasse para saber se, sim ou não, nossos sujeitos fazem a diferença entre polidez e demais normas morais. Se nos basearmos nos conteúdos associados à polidez, a resposta é negativa para a maioria deles, mas se levarmos em conta os resultados referentes ao que deve ser feito com a pessoa não polida, a resposta é diferente: pelo menos metade dos sujeitos de todas as faixas etárias distinguem a falta polidez da falta moral. Há mais: sujeitos que, embora tendo dado exemplos de não polidez relacionados a infrações como roubar e mentir, sugerem educação, e não castigo, para os mal-educados. Há, portanto, flutuação nos dados: dependendo da pergunta aberta, alguns sujeitos associam a polidez à moralidade em geral e, provavelmente levando em conta sua experiência pessoal, identificam-na como falta de boas maneiras. A variável experiência pessoal é relevante aqui: muitas crianças certamente não são castigadas (talvez sejam apenas repreendidas, notadamente com a expressão "criança mal-educada") quando faltam à polidez, mas o são quando agridem fisicamente alguém ou mentem. Logo, quando levadas a pensar nas reações sociais à má educação, avaliam melhor sua especificidade. Em compensação, quando devem, espontaneamente, definir, com exemplos, o que é a polidez, ocorrem-lhes a pessoa que foge às regras básicas de convívio. Em resumo, haveria, para os sujeitos das três faixas etárias pesquisadas, certa ambigüidade das singu- 
laridades da polidez e de suas relações com o universo moral: pelo menos para metade dos sujeitos, a polidez nem é totalmente moral, nem deixa de pertencer ao universo ético.

Precisamos, portanto, de mais dados para conhecer as representações que crianças de diversas idades fazem da polidez. Os estudos 2 e 3 vão nos fornecer dados bem claros a este respeito.

\section{Estudo 2}

Colocamos a nossos sujeitos uma pergunta precisa: sabendo-se que uma pessoa costuma não se desculpar, não pedir por favor etc., será que se pode prever que transgredirá normas como não quebrar objetos alheios? Ou seja, será que a presença ou ausência de polidez traduz a índole moral de uma pessoa? Note-se que, para fugir à possível ambigüidade da expressão "bem-educado", nossa história coloca claramente o que é falta de polidez.

Vejamos os resultados referentes à "história do canteiro" (tabela 4): os sujeitos tiveram de dizer se, segundo eles, a pessoa que havia pisado um canteiro de flores era a personagem mal-educada ou a outra, a polida.

TABELA 4

PORCENTAGEM DE SUJEITOS QUE JULGAM SER A CRIANÇA

MAL-EDUCADA OU A BEM-EDUCADA, OU AINDA QUALQUER UMA DAS DUAS, QUE PISOTEOU UM CANTEIRO (N=30 PARA CADA FAIXA ETÁRIA)

\begin{tabular}{|l|c|c|c|}
\hline & 6 anos & 9 anos & 12 anos \\
\hline O bem-educado & $0 \%$ & $0 \%$ & $0 \%$ \\
\hline O mal-educado & $100 \%$ & $86,2 \%$ & $36,7 \%$ \\
\hline Não se pode saber & $0 \%$ & $13,8 \%$ & $63,3 \%$ \\
\hline
\end{tabular}

Como dissemos, os resultados são claros: para as crianças menores (6 anos), a má educação de uma pessoa sugere que esta transgredirá leis outras que as da polidez. A porcentagem referente a este juízo ainda é alta para os sujeitos de 9 anos $(86,2 \%)$ e cai para $36,7 \%$ para aqueles de 12 anos. Para sabermos se as respostas apenas revelam uma suposição ou se decorrem de uma dedução, pedimos também a nossos sujeitos que dissessem se tinham ou não certeza do que afirmavam. A tabela 5 mostra os resultados da pergunta. A diferença entre as repostas das faixas etárias confirma-se. 
TABELA 5

PORCENTAGEM DE SUJEITOS QUE JULGAM TER CERTEZA DE QUE A FALTA OU PRESENÇA DE POLIDEZ POSSIBILITA SABER QUEM PISOTEOU UM CANTEIRO ( $\mathbf{N}=30$ PARA CADA FAIXA ETÁRIA)

\begin{tabular}{|l|c|c|c|}
\hline & 6 anos & 9 anos & 12 anos \\
\hline Tem certeza & $66,7 \%$ & $27,6 \%$ & $0 \%$ \\
\hline Não tem certeza & $20 \%$ & $72,4 \%$ & $100 \%$ \\
\hline Não sabe & $13,3 \%$ & $0 \%$ & $0 \%$ \\
\hline
\end{tabular}

Em resumo, os resultados da primeira parte do estudo 2 mostram que, para as crianças de 6 anos, a falta de polidez é um indício confiável para se prever outras transgressões. Para as crianças de 12 anos, tal certeza desaparece por completo (0\%). A segunda parte desse estudo confirma esses dados: solicitados a dizerem quem eles acham que quebrou o vaso, 73\% das crianças de 6 anos apontaram o mal-educado, enquanto 93,\% e 100\% de 12 anos afirmaram não poder saber quem foi.

\section{Estudo 3}

Antes de comentarmos os dados, vejamos os do estudo 3, de mesma estrutura que o anterior, porém com uma diferença importante: enquanto no estudo 2 colocamos um dano material, portanto a transgressão a uma regra precisa e que prejudica outrem de forma mediada (pelo objeto quebrado), no estudo 3 colocamos a ausência de virtudes cujo efeito é deixar outrem em dificuldades: com efeito, ao deixar de ajudar alguém ameaçado, a personagem pode ser vista como covarde, ou não generosa, ou ainda como não justa. A pergunta foi: podemos saber se quem ajudou a pessoa em dificuldade (apanhar de um grupo) foi o menino mal-educado ou o outro, bem-educado? Os dados confirmam aqueles do estudo anterior (tabelas 6 e 7). 
TABELA 6

PORCENTAGEM DE SUJEITOS QUE JULGAM SER O MENINO BEM-EDUCADO OU O MAL-EDUCADO, OU AINDA QUALQUER UM DOS DOIS, QUE AJUDOU ALGUÉM EM DIFICULDADES (N=30 PARA CADA FAIXA ETÁRIA)

\begin{tabular}{|l|c|c|c|}
\hline & 6 anos & 9 anos & 12 anos \\
\hline O bem-educado & $96,7 \%$ & $82,8 \%$ & $53,3 \%$ \\
\hline O mal-educado & $0 \%$ & $0 \%$ & $3,30 \%$ \\
\hline $\begin{array}{l}\text { Qualquer um (não se } \\
\text { pode saber) }\end{array}$ & $3,3 \%$ & $17,2 \%$ & $43,7 \%$ \\
\hline
\end{tabular}

TABELA 7

PORCENTAGEM DE SUJEITOS QUE JULGAM TER CERTEZA DE QUE A FALTA OU PRESENÇA DE POLIDEZ POSSIBILITA SABER QUEM AJUDOU ALGUÉM ( $\mathbf{N}=30$ PARA CADA FAIXA ETÁRIA)

\begin{tabular}{|l|c|c|c|}
\hline & 6 anos & 9 anos & 12 anos \\
\hline Tem certeza & $70 \%$ & $24,2 \%$ & $13,3 \%$ \\
\hline Não tem certeza & $26,7 \%$ & $72,4 \%$ & $86,7 \%$ \\
\hline Não sabe & $3,3 \%$ & $3,4 \%$ & $0 \%$ \\
\hline
\end{tabular}

Nas linhas gerais, os resultados dos estudos 2 e 3 são convergentes: na gênese da moralidade, a presença da polidez é um indício praticamente certo de que a pessoa polida comporta-se bem em geral, seja não transgredindo regras, seja mostrando-se solidário, generoso ou corajoso. Tal fato é certamente rico para respondermos à nossa indagação geral a respeito do lugar da polidez no universo moral das crianças. Vejamos o porquê.

No estudo I, pedimos a nossos sujeitos que fizessem um juízo de valor (que condutas podem ser consideradas polidas e o que se deve fazer com o maleducado); nos estudos 2 e 3, pedimo-lhes um juízo de realidade (prever a conduta de pessoas bem ou mal-educadas), e esse juízo incidiu sobre a personalidade moral ou caráter. Com efeito, prever boas ou más ações de alguém é julgar se trata-se de uma boa pessoa, de alguém respeitoso e confiável. Ora, uma vez que a literatura psicológica tem nos acostumado a pensar o desenvolvimento moral quase que exclusivamente a partir dos juízos de valor de crianças e adolescentes, podemos nos perguntar se levar em conta juízos de realidade sobre a índole moral das pessoas tem alguma relevância para o estudo do referido desenvolvimento. Ora, acreditamos que sim pelas seguintes razões. 
A primeira: juízos de realidade do tipo que estamos analisando depende de juízos de valor, porque inferir, a partir da constatação de algumas condutas que determinada pessoa vai comportar-se bem ou mal, implica julgar o caráter dessa pessoa. É o que fizeram nossos sujeitos de 6 anos e ainda boa parte dos de 9 anos: a pessoa que mostra falta de educação é também aquela que quebra objetos alheios e não socorre alguém em dificuldades. Como não há relação direta entre polidez e honestidade, generosidade ou coragem, é razoável pensar que nossos sujeitos fizeram a hipótese que as personagens apresentadas são "boas" ou "más" e, logo, agiram bem ou mal. Os estudos 2 e 3, portanto, revelam, indiretamente, como as crianças julgam não os atos, mas as pessoas, e isto tem importância para compreendermos a gênese da moral. É justamente a segunda razão pela qual acreditamos que nossos dados têm relevância: parece-nos justificado pensar que a criança constrói sua moralidade não apenas refletindo sobre as regras e os valores (o certo e o errado), mas também - e talvez essencialmente - observando e avaliando as pessoas que, em volta, agem de diferentes maneiras. Piaget (1992) já afirmava que a criança heterônoma respeita certas regras porque respeita as pessoas que as impuseram, respeito este formado a partir de uma fusão entre o medo e a admiração. Em uma palavra, pelo menos no início do desenvolvimento moral, a avaliação do caráter das pessoas é indissociável da avaliação moral. E há mais: Tugendhat (1993), que já citamos, certamente tem razão ao afirmar que o despertar e o fortalecimento do sentimento de confiança é essencial à entrada da criança no universo moral. Evidentemente, tal sentimento é experimentado em relação a pessoas que são vistas pela criança como "boas". Em resumo, conhecer os juízos que as crianças fazem não apenas das regras, mas também das pessoas, parecenos necessário para estudar a gênese da moralidade. $O$ que mostraram nossos dados? Mostram que a polidez faz parte das "pistas" que a criança menor emprega para julgar as pessoas. Essa é a terceira razão que nos faz sustentar a relevância de nossos dados. É provável que, no início do desenvolvimento, a criança trace uma fronteira entre "boas pessoas" e "más pessoas", sem demais nuanças. Retomando a expressão consagrada, é possível que ela siga a hipótese do "pacote de virtudes": quem tem uma, tem todas. Todavia, nossos dados não nos permitem ter certeza do fato pois, para tanto, seria preciso verificar se, para as crianças menores, por exemplo, uma pessoa generosa é necessariamente justa, se uma pessoa justa sempre também é generosa, se uma pessoa grata age em concordância com as demais virtudes, e assim por diante. Mas o que podemos afirmar a partir de nossa pesquisa é que a polidez é uma virtude cujo exercício permite à maioria das crianças de até 9 anos julgar o caráter de alguém. Logo, se aceitarmos a hipótese 
segundo a qual o juízo sobre o caráter das pessoas é elemento importante para o desenvolvimento moral, podemos concluir que a polidez não somente faz parte do universo moral das crianças como é valor destacado para julgarem moralmente as pessoas que estão próximas e, por conseguinte, para julgarem a si mesmas.

\section{Estudo 4}

Os estudos 2 e 3 mostraram que, aos 12 anos de idade, as crianças deixam de ver na polidez um sólido índice para se julgar a índole moral de uma pessoa. Mas vimos no estudo I que, mesmo nessa idade, a boa educação é associada ao respeito de regras claramente morais (não bater, não mentir etc.). Vamos então pedir a nossos sujeitos que comparem a gravidade de dois atos: um é a falta de polidez (não dizer obrigado), outro é quebrar um objeto alheio por desleixo. A tabela 8 nos mostra os resultados da pergunta feita a respeito da gravidade das duas condutas.

\section{TABELA 8}

PORCENTAGEM DE SUJEITOS QUE JULGAM SER A FALTA DE POLIDEZ MAIS GRAVE QUE O DANO MATERIAL OCASIONADO POR DESLEIXO, ESTE ÚLTIMO MAIS GRAVE QUE A PRIMEIRA, OU AMBOS DE GRAVIDADE EQÜIVALENTE ( $\mathbf{N}=\mathbf{3 0}$ PARA CADA FAIXA ETÁRIA)

\begin{tabular}{|l|c|c|c|}
\hline & 6 anos* & 9 anos & 12 anos \\
\hline Falta de polidez & $53,3 \%$ & $55,2 \%$ & $66,6 \%$ \\
\hline Dano material & $30,3 \%$ & $6,9 \%$ & $16,7 \%$ \\
\hline Eqüivalente & $13,3 \%$ & $37,9 \%$ & 16,7 \\
\hline
\end{tabular}

* Um sujeito de 6 anos afirmou não saber responder.

Como se vê, em todas as faixas etárias a falta de polidez é considerada mais grave que o dano material ocasionado por um desleixo. Será por que o dano material é considerado, em geral, pouco grave? Escolhemos compará-lo à falta de polidez por algumas razões simples. Em primeiro lugar, porque pareceu-nos mais adequado para a comparação do que delitos como mentir ou roubar que, além de ferirem diretamente a vítima, têm um peso cultural forte. Assim, o dano material ocasionado por desleixo, embora passível de reprovação moral (todos os nossos sujeitos, respondendo a uma pergunta específica, afirmaram que o menino que deixou cair a xícara de açúcar havia agido mal), costuma não representar uma falta 
grave. Em segundo lugar, escolhemos o dano material por ser acontecimento freqüente na vida das crianças. Em terceiro e último lugar, escolhemos esse delito por sabermos, a partir das pesquisas de Piaget ( 1992), que as crianças menores Ihe dão mais importância que à intencionalidade. Com base nisso, verificamos que, mesmo para as crianças menores, a falta de polidez é vista como mais grave por metade da amostra. Os argumentos apresentados pelos sujeitos que escolheram a falta de polidez mostra que, para os sujeitos de 6 anos, 62,5\% dizem que tal falta é pior que um dano material ocasionado por um desleixo, e 25\% afirmam que, como não houve intenção de quebrar a xícara, o acontecido não foi tão grave assim ( 1 2,5\% desses sujeitos não souberam explicar sua escolha). Aos 9 e 12 de idade, respectivamente $56,3 \%$ e $45 \%$ dos sujeitos julgam a falta de polidez como mais grave enquanto 43,7 (9 anos) e 55\% ( 12 anos) pensam que a falta de intencionalidade reduz a gravidade do ato. Em resumo, os resultados do estudo 4 mostram que a falta de polidez (no exemplo apresentado - não agradecer) é vista como delito digno de nota, merecendo, para pelo menos metade dos sujeitos, mais reprovação que um desleixo seguido de conseqüências materiais ${ }^{10}$.

\section{CONCLUSÕES: A POLIDEZE A EDUCAÇÃO MORAL}

A pesquisa que acabamos de relatar tinha como objetivo trazer primeiros dados para responder a duas perguntas: qual o lugar da polidez no universo moral das crianças de 6 a 12 anos e qual a sua singularidade em relação a outras regras e valores. Podemos concluir o que segue:

- a polidez pertence ao universo moral das crianças de 6 a 12 anos (Estudos I e 4);

- a opção pela educação (e não o castigo) como reação à falta de polidez mostra sua singularidade nas faixas etárias de 9 e 12 anos, e a opção já está presente na metade da amostra de 6 anos (estudo I);

10. É possível fazer uma ressalva à nossa história referente ao menino mal-educado: talvez pelo fato de termos colocado que, além de não dizer obrigado, ele vira as costas e vai embora, tenhamos "forçado" um pouco a descrição do desrespeito. Talvez se tivéssemos apenas dito que faltou dizer obrigado, os juízos negativos de nossos sujeitos teriam sido mais brandos. Será o caso de refazer a pesquisa com a simples menção à ausência do agradecimento. Mas, enquanto não for refeita, pensamos que é válido construir a hipótese de que a falta de polidez tem peso apreciável no juízo moral das crianças: afinal, o "virar as costas" também é sinal de falta de educação e não uma falta moral como roubar ou mentir. 
- a falta de polidez é, para as crianças de 6 anos, um indício para se julgar o caráter (moral) de uma pessoa e deixa de sê-lo para as crianças de 12 anos, com uma fase de transição para os 9 anos (estudos 2 e 3);

- a falta de polidez é vista como conduta de certa gravidade nas três faixas etárias (estudo 4).

Em resumo, nossos dados levam a pensar que a polidez tem lugar relevante na gênese da moralidade, pois pertence ao conjunto de valores e regras com os quais a criança penetra o universo moral e sobre os quais reconstrói esse universo em direção à autonomia. A virtude polidez deve, então, ser objeto da educação moral? É o último ponto que devemos analisar.

Antes de mais nada, devemos ter consciência de que o tema da educação moral na escola é complexo e polêmico, para não dizer perigoso. É complexo porque o agir e pensar morais dependem de inúmeros fatores psicológicos, notadamente de uma articulação entre razão e afetividade. Cremos ser honesto admitir que, apesar de praticamente cem anos de pesquisas psicológicas sobre as formas como um indivíduo legitima um conjunto de valores e regras, ainda há mais mistérios do que certezas nessa área do conhecimento. É polêmico porque, em tal educação, estão em jogo valores nem sempre consensuais. E é perigoso porque, dependendo da estratégia pedagógica empregada, pode-se meramente criar seres conformistas, obedientes e subservientes a uma ordem ideológica estabelecida, aceita sem crítica. Ora, é justamente esse perigo que devemos ter em mente ao acreditarmos que uma educação que contemple as virtudes pode enriquecer a educação moral. Com efeito, a rigor não há nada mais antigo do que uma educação moral realizada por meio do "ensino" das virtudes. Nas últimas décadas, tem caído em desuso por pelo menos duas razões. A primeira é sua ineficiência. Esta já tinha sido, há quase três séculos, apontada por Rousseau (1966): a moral não pode ser ensinada de forma verbal e/ou pela mera cópia de modelos. Ora, a pedagogia clássica das virtudes fazia exatamente o que Rousseau criticava: por meio de belas histórias, com santos e heróis, ou modelos, em geral concluídas por uma "moral da história" ou frases de impacto, procurava-se ensinar a separar o bem do mal, o certo do errado. No entanto, as pesquisas psicológicas e as experiências pedagógicas tenderam a mostrar que a construção da moralidade dá-se bem mais na vida cotidiana, na experiência ética, nas relações de cooperação do que pela contemplação de modelos edificantes. Estes podem servir de inspiração, de emulação, mas não substituem a praxis (ver Piaget, 1998; Puig, 1998). A segun- 
da causa do abandono de uma "pedagogia das virtudes" foi o perigo do autoritarismo, do disciplinar dos corpos e das almas. Tal perigo apresenta-se sob duas faces. A primeira é correlata da ineficiência: ao invés de levar ao desenvolvimento da autonomia moral (ou ao alcance do nível pós-convencional), práticas meramente verbais de educação moral, quando têm algum efeito, freqüentemente levam ao conformismo, à obediência, em uma palavra, à heteronomia. A segunda diz especificamente respeito às virtudes: com exceção da justiça, que pode ser exigida de cada um, por traduzir um direito alheio, as demais estão estritamente sob a égide da liberdade. Portanto, impor seu exercício é ferir a liberdade do sujeito.

As desconfianças em relação à educação moral, principalmente aquela que almejava a "formação do caráter" levaram, entre outros motivos (notadamente políticos), seja a um puro e simples abandono da educação moral nas escolas (é o caso, hoje, da maioria das instituições educacionais brasileiras), seja à criação de novas estratégias entre as quais dominam as seguintes: o estímulo ao trabalho em grupo para promover relações sociais de cooperação (é o conselho pedagógico de Piaget, 1998), a discussão de dilemas morais (primeira opção colocada por Kohlberg, 1987), jogos em grupo (proposta de Kamii, I99।, para crianças pequenas), fazer da escola uma comunidade justa, na qual se estabeleçam contratos entre alunos, professores e funcionários (também proposta de Kohlberg, que lembra o estilo pedagógico da escola Summerhill, ver Singer, 1997), os "combinados" entre os alunos e assembléias de classe (ver Puig, 1998a) e a tranversalidade (proposta" pelos Parâmetros Curriculares Nacionais Brasileiros, ver Brasil, 1997). O que essas diversas propostas têm em comum são, em linhas gerais, a ausência de aulas específicas de educação moral, a ausência apresentação de modelos, o diálogo entre os alunos, a busca de contratos de convivência e, em decorrência dessa visão contratual da moral, a sua definição no que diz respeito a direitos e deveres. Com exceção da justiça, as demais virtudes são as grandes ausentes dessas propostas pedagógicas contemporâneas.

É difícil avaliar os resultados educacionais dessas propostas ${ }^{12}$. Aliás, quantas escolas realmente as implementam? O que se pode dizer com razoável certeza é que, nos dias de hoje, um mal-estar ético está instalado na educação (e na sociedade como um todo), mal-estar este que se traduz por queixas dos professores

I I. A proposta da transversalidade foi inicialmente feita no currículo da Espanha.

12. Sobre alguns resultados das propostas de discussão de dilemas e organização de comunidades justas, ver Freitag, 1992. 
sobre a indisciplina dos alunos, sobre seus comportamentos desrespeitosos, sua incivilidade, sua agressividade e violência. Na esteira dessas queixas, certo saudosismo instalase, com muitos pais procurando escolas mais "disciplinadoras". Sintomaticamente, o tema das virtudes volta à cena, como o atestam publicações recentes como os "livros das virtudes" organizados por Bennett (1995, 1995a, 1997). Ora, em razão do que escrevemos na introdução teórica deste artigo, pensamos que a retomada da preocupação pedagógica em torno das virtudes pode enriquecer o campo da educação moral. Todavia, é preciso evitar a cilada de retornar a um prática que, por bons motivos, foi abandonada. É, por exemplo, o que podemos temer, hoje, do emprego pedagógico dos "livros das virtudes" que acabamos de citar. Lá encontram-se alguns belos textos, mas, infelizmente, eles já vêm "pré-classificados". Segundo o critério de Bennett, uns tratariam de coragem, outros de fidelidade, outros ainda de generosidade. Ora, basta ler os textos para perceber que tal classificação é, para dizer o mínimo, discutível. E, sobretudo, melhor seria deixar as crianças elas mesmas refletirem sobre os sentidos que extraem dos textos, permitindoIhes construírem suas representações a avaliações das diversas virtudes (La Taille, 1998). É nessa perspectiva que vemos uma educação moral que, juntamente com a cooperação, a comunidade justa e a chamada "transversalidade", não despreze as virtudes, desprezo que, voltamos a dizê-lo, parece-nos empobrecer a ética.

Mas falar abstratamente em virtudes não é suficiente. É preciso que a educação se debruce sobre a singularidade de cada uma delas, tanto do ponto de vista de pesquisas empíricas a respeito de seu lugar no universo moral infantil e adolescente, como da elaboração de práticas pedagógicas particulares. Fechamos então nosso texto tecendo algumas considerações sobre o lugar da polidez na educação.

Cremos que nossos dados depõem a favor de um cuidado especial para a prática da polidez, já durante a infância. Vimos que para Comte-Sponville, ela é a "primeira virtude" no sentido de preceder as demais. Porém, pelo que se sabe em psicologia moral, as primeiras noções de justiça também são precoces assim como o são noções de generosidade, gratidão, humildade, fidelidade e coragem (temos dados ainda não publicados que atestam que essas virtudes já fazem parte do universo moral da criança pequena). Portanto, a polidez não pode ser vista como a única virtude (ou "pequena virtude") pela qual a criança adentra o terreno da moral. Mas, como verificamos, ela já está presente no início do desenvolvimento, assemelhando-se a outras regras morais, considerando sua falta problemática, desrespeitosa e indício da má índole moral. Ora, tais dados credenciam a polidez para que conste dos valores a serem trabalhados pela educação moral. Há quatro razões que nos levam a esta afirmação: 
I. A perspectiva pedagógica inspirada no construtivismo piagetiano reza que não se deve ignorar as representações espontâneas ${ }^{13}$, sob pena de não somente negar elaborações intelectuais ricas das crianças como dificultar o desenvolvimento, uma vez que este é sempre uma superação de noções anteriores (e não uma simples troca de noções antigas por novas). Portanto, se a criança pequena elege o tema da polidez como tema de reflexão e, como vimos, esse conjunto de valores e regras têm, para ela, dimensões morais, a educação não pode ignorar o fato.

2. Como assinalado anteriormente em nosso texto, a polidez é formada de um conjunto de regras simples, de contornos precisos, cujo emprego não pressupõe necessariamente sinceridade. Dito de outra maneira, o emprego das regras da boa educação pode muito bem contentar-se com uma interpretação ao "pé da letra". Ora, tal interpretação é uma das características centrais da heteronomia moral infantil ou do estágio préconvencional. Logo, a polidez pode perfeitamente integrar o universo moral infantil e ser adequada aos níveis inferiores de desenvolvimento moral. Vale dizer que a criança pequena pode muito bem compreender o que é a polidez. E pode também começar a compreender que, por detrás de algumas fórmulas prontas da boa educação, estão outras virtudes mais sofisticadas e claramente morais (se não restringimos a moral à virtude justiça). Por exemplo, o "desculpe" aponta para o reconhecimento do erro (a confissão é um elemento crucial no desenvolvimento da personalidade moral, ver La Taille, 2000); o "obrigado" aponta para a gratidão; o "por favor" aponta para a solicitação da generosidade alheia e para a humildade (a dependência em relação a outrem); o "bom-dia" e o "até logo" apontam para a amizade, e assim por diante ${ }^{14}$. É claro que tais fórmulas são apenas um simulacro das virtudes apontadas, ou estão apenas na sua face exterior. Mas, como o desenvolvimento segue sempre o caminho

13. O adjetivo "espontâneo" não significa que as representações não tenham sido induzidas pela cultura, significa apenas que elas são assimiladas pelo sujeito que as traduz em elaborações típicas das diferentes fases do seu desenvolvimento.

14. Tanto é verdade que certas fórmulas de polidez apontam para aspectos importantes das relações sociais é que duas pessoas "brigadas" às vezes marcam sua diferença pelo abandono do cumprimento habitual ("bom-dia", "até logo") mas podem, se forem obrigadas a conviver (por 
dos aspectos superficiais dos objetos (sentido epistemológico) para aspectos centrais, parece-nos que a polidez pode oferecer um terreno sólido para que o juízo moral possa construir-se ${ }^{15}$.

3. Como também assinalado anteriormente, a polidez não é de todo desprovida de valor moral, uma vez que seu uso pode traduzir expressão de respeito por outrem (seu não uso é claramente expressão de desrespeito) e traduzir uma relação de igualdade. Assim, como outras formas de respeito, a polidez pode fazer parte da formação moral das crianças.

4. Finalmente, lembremos que, para as crianças menores, a presença ou ausência de polidez é um critério empregado para julgar o caráter moral das pessoas. Como a construção da moral não se restringe à reflexão sobre regras e atos, mas também sobre o caráter das pessoas (ver Piaget, 1992, Tugendhat, 1993) e como o exercício da polidez é, como verificamos, um critério que as crianças menores empregam para julgar pessoas, cremos que não ignorar esta leitura infantil da "personalidade moral" impõe-se a quem quer pensar uma educação moral inspirada nos dados que a psicologia pode trazer à tona.

Como fazer? Qual a pedagogia desejada? Não cabe ao psicólogo, que somos, decidir sob pena de invadir uma área do conhecimento e da prática que exige competências singulares advindas de uma formação acadêmica (e também prática) singular. Limitamo-nos a submeter aos educadores nossas reflexões e dados sobre desenvolvimento moral, virtudes e, em especial, polidez.

\section{REFERÊNCIAS BIBLIOGRÁFICAS}

exemplo no trabalho), permanecer empregando entre elas fórmulas como "desculpe" ou "por favor". O não emprego destas últimas poderia ser interpretado como falta de respeito (portanto uma dimensão moral), enquanto o não emprego de fórmulas de cumprimento assinala somente o desaparecimento de relações afetivas positivas.

15. Às vezes, algumas crianças empregam formas de polidez como "palavras mágicas" para escapar a situações de castigo ou responsabilidade: por exemplo, falar mecanicamente "desculpa" após uma transgressão acreditando que tal expressão apaga automaticamente os efeitos da conduta. Tal emprego espontâneo da polidez pode ser a base de um trabalho pedagógico a respeito do valor e alcance dessa virtude. 
ARISTOTE. Ethique de Nicomade. Paris: Flamarion, 1965.

BENNETT, W. J. O Livro das virtudes. Rio de Janeiro: Nova Fronteira, 1995.

O Livro das virtudes II. Rio de Janeiro: Nova Fronteira, I995a.

O Livro das virtudes para crianças. Rio de Janeiro: Nova Fronteira, 1997.

BLASI, A. The Development of identity: some implications for moral functioning. In: NOAM, G. G.; WREN, E. (org.). The Moral self. Cambridge: The Mit Press, 1993. p. 99-122.

Moral understanding and the moral personality: the process of moral integration. In: KURTINES (org.). Moral development. an introduction. London: Allyn and Bacon, 1995. p. 229-54.

BRASIL. Ministério da Educação e Cultura. Parâmetros Curriculares Nacionais. Brasília: Secretaria de Educação Fundamental, 1997.

CAMPBELL, R.; CRISTOPHER, J. Moral development theory: a critique of its kantian presupositions. Developmental review, v. I6, n. I, p. I-47, 1996.

COLBY, A.; DAMON, W. The Uniting of self and morality in the development of extraordinary moral commitment. In: NOAM, G. G.; WREN, E. (org.). The Moral self. Cambridge: The Mit Press, 1993. p.49-174.

COMTE-SPONVILLE, A. Petit traité des grandes vertus. Paris: PUF, 1995.

DURKHEIM, E. L'Éducation morale. Paris: PUF, 1974.

FLANAGAN, O. Psychologie morale et éthique. Paris: PUF, 1996.

FREITAG, B. Itinerários de Antígona: a questão da moralidade. Campinas: Papirus, 1992.

FREUD, S. Le Moi et le ça. Paris: PUF, 199I.

GILLIGAN, C. Uma voz diferente. Rio de Janeiro: Rosa dos Ventos, 1982.

Remaping the moral domain: new images of self and relationship. In:

GILLIGAN, C.; WARD, J. V.; TAYLOR, J. M. C. L. (orgs.). The Moral domain. Havard: Havard University Press, 1988. p.3-20.

HABERMAS, J. Morale et communication: conscience morale et activité communicationnelle. Paris: Editions du Cerf, 1986.

KAMII, C.; DEVRIES, R. Jogos em grupo na educação infantil. São Paulo: Trajetória Cultural, |991.

KANT, E. Métaphysique des moeurs, première partie. Paris: Flamarion, 1994.

Métaphysique des moeurs, deuxième partie: doctrine des vertus. Paris: Vrin, 
1985.

Traité de pédagogie. Paris: Hachette, 1981.

KOHLBERG, L. Essays on moral development. S. Francisco: Harper \& Row, 1981, 1984, 1987.

LA TAILLE, Y. Limites. três dimensões educacionais. São Paulo: Ática, 1998. Vergonha, a ferida moral. São Paulo, 2000. Tese (Livre Doc.) USP.

LATERMAN, I. Violências, incivilidades e indisciplinas no meio escolar. um estudo em duas escolas da rede pública. Florianópolis: Letras Contemporâneas, 2000.

LUCCHESI-BELZANE, M. Un Vide essentiel. La Politesse. n. 2, p. 28-44, fev. 199I. (Série morale)

MACINTYRE, A. After virtue: a study in moral theorie. London: University of Notre Dame Press, 1981.

PERRON, R. Les Représentations de soi. Toulouse: Privat, I991.

PIAGET, J. De la pédagogie. Paris: Odile Jacob, 1998.

Études sociologiques. Paris: Droz, 1977.

Le Jugement moral chez l'enfant. Paris: PUF, 1992.

PUIG J. M. R. A Construção da personalidade moral. São Paulo: Ática, 1998.

Ética e valores. métodos para um ensino transversal. São Paulo: Casa do

Psicólogo, 1998a.

RAWLS, J. Théorie de la justice. Paris: Seuil, I97I.

ROUSSEAU, J. J. Emile ou de l'éducation. Paris: Garnier-Flammarion, 1966.

SENNETT, R. A Corrosão do caráter. conseqüências pessoais do trabalho no novo capitalismo. Rio de Janeiro: Record, 1999.

SINGER, H. República de crianças. São Paulo: Hucitec; Fapesp, 1997.

TAYLOR, C. Les Sources du moi. Paris: Seuil, 1998.

TUGENDHAT, E. Lições sobre ética. Rio de Janeiro: Vozes, 1993.

TURIEL, E. The Development of social knowledge: morality and convention. Cambridge:

Cambridge University Press, 1983. 